\title{
Boreal and temperate trees show strong acclimation of respiration to warming
}

\author{
Peter B. Reich ${ }^{1,2}$, Kerrie M. Sendall ${ }^{1}$, Artur Stefanski ${ }^{1}$, Xiaorong Wei ${ }^{1,3}$, Roy L. Rich ${ }^{1,4}$ \& Rebecca A. Montgomery ${ }^{1}$
}

Plant respiration results in an annual flux of carbon dioxide $\left(\mathrm{CO}_{2}\right)$ to the atmosphere that is six times as large as that due to the emissions from fossil fuel burning, so changes in either will impact future climate. As plant respiration responds positively to temperature, a warming world may result in additional respiratory $\mathrm{CO}_{2}$ release, and hence further atmospheric warming ${ }^{1,2}$. Plant respiration can acclimate to altered temperatures, however, weakening the positive feedback of plant respiration to rising global air temperature ${ }^{3-7}$, but a lack of evidence on long-term (weeks to years) acclimation to climate warming in field settings currently hinders realistic predictions of respiratory release of $\mathrm{CO}_{2}$ under future climatic conditions. Here we demonstrate strong acclimation of leaf respiration to both experimental warming and seasonal temperature variation for juveniles of ten North American tree species growing for several years in forest conditions. Plants grown and measured at $3.4^{\circ} \mathrm{C}$ above ambient temperature increased leaf respiration by an average of $5 \%$ compared to plants grown and measured at ambient temperature; without acclimation, these increases would have been $23 \%$. Thus, acclimation eliminated $80 \%$ of the expected increase in leaf respiration of non-acclimated plants. Acclimation of leaf respiration per degree temperature change was similar for experimental warming and seasonal temperature variation. Moreover, the observed increase in leaf respiration per degree increase in temperature was less than half as large as the average reported for previous studies ${ }^{4,7}$, which were conducted largely over shorter time scales in laboratory settings. If such dampening effects of leaf thermal acclimation occur generally, the increase in respiration rates of terrestrial plants in response to climate warming may be less than predicted, and thus may not raise atmospheric $\mathrm{CO}_{2}$ concentrations as much as anticipated.

Rising global temperatures (of $1.1-6.4^{\circ} \mathrm{C}$ by 2100 ) will probably result in a positive terrestrial feedback to the global carbon cycle, because respiratory flux to the atmosphere from soils and plants is anticipated to increase more with warming than is the rate of gross primary production $(\mathrm{GPP})^{5,6}$. Respiration in terrestrial plants releases approximately $64 \mathrm{Gt}$ of carbon each year to the atmosphere ( six times the amount of fossil fuel emissions), directly offsetting roughly half of the GPP of terrestrial ecosystems ${ }^{5,6}$, so even a small fractional change in total plant respiration with climate warming could be important for both global net productivity and the carbon content of the atmosphere. If long-term net respiratory fluxes from terrestrial ecosystems follow the near-exponential short-term relationship of respiration to temperature ${ }^{3}$, climate warming will trigger a sharp increase in ecosystem respiration. Such an increase in $\mathrm{CO}_{2}$ release would probably be greater than the offsetting increase in GPP, because GPP tends to show a saturating, hump-shaped response to rising temperature. This would result in a heightened net $\mathrm{CO}_{2}$ release from terrestrial ecosystems, and further atmospheric warming ${ }^{1,2}$.
Plants, however, can dynamically adjust the response of respiration to temperature over the long term (weeks to years), even though plant respiration always shows an accelerating increase when subjected to a short-term (minutes to hours) increase in temperature. Typically, a plant that has experienced warmer temperatures will have a lower rate of respiration at a standardized measurement temperature than a plant that has experienced cooler temperatures (Extended Data Fig. 1). This process is labelled thermal acclimation ${ }^{3,4,7}$. The greater the thermal acclimation of respiration globally, the smaller the positive feedback between climate warming and ecosystem $\mathrm{CO}_{2}$ release $\mathrm{e}^{3,7,8}$. Thermal acclimation of plant respiration has been noted in most, but not all, cases studied ${ }^{3,7-13}$, but the degree of acclimation is extremely uncertain $^{3,7-13}$, especially for plants in natural settings. Such information will be crucial for making better predictions of terrestrial feedbacks ${ }^{14,15}$. The need for ecologically realistic acclimation generalizations is clear, because current state-of-the-art models ${ }^{16,17}$ predict acclimation based on a study of first-year seedlings grown for $2-3$ months at constant $7,14,21$ and $28^{\circ} \mathrm{C}$ conditions in growth cabinets ${ }^{4}$. Hence, observations of acclimation of plants grown in more realistic field settings (for as long as 5 years), as presented here, should provide a meaningful advance.

High latitude boreal and temperate forests account for approximately one-third of Earth's total forest area, and have an important role in terrestrial carbon cycling ${ }^{4,5,13-15}$. To advance understanding of carbon cycling in a changing climate, we assessed the acclimation capacity of more than 1,200 individuals of 10 dominant North American tree species grown in ambient and warmed $\left(+3.4^{\circ} \mathrm{C}\right)$ plots in a free-air warming experiment ${ }^{18,19}$. We present the results of 1,620 leaf respiration-temperature response curves ${ }^{3,20-22}$ made from 2009 to 2013 in both open and understory forest habitats at two sites $(\sim 150 \mathrm{~km}$ apart) at the boreal-temperate forest ecotone in Minnesota, USA. Species were measured in three $(n=4)$, four $(n=2)$ or all five $(n=4)$ years. Temperatures measured for each response curve ranged from 12 to $37^{\circ} \mathrm{C}$ in 5 -degree intervals (see Methods). Because the shape of the short-term temperature response curves did not vary with warming treatment for any of the species (see later), comparing the curves of plants from warmed and ambient treatments enables assessment of the magnitude of thermal acclimation in response to experimental warming. Additional information is gained by comparing the curves of plants measured at different times during the growing season; that is, assessing how much lower leaf respiration is at a given measurement temperature in a warm spell compared to a cold spell.

We focus on the magnitude of acclimation induced by experimental warming as well as the magnitude of acclimation comparing warmer to cooler time periods. For example, if a plant grown at $20^{\circ} \mathrm{C}$ increased leaf respiration $\left(R_{\text {leaf }}\right)$ by $40 \%$ after being moved to $25^{\circ} \mathrm{C}$ for $30 \mathrm{~min}$, but had the same rate after 3 weeks at $25^{\circ} \mathrm{C}$ as initially when grown and measured at $20^{\circ} \mathrm{C}$, it would have completely (100\%) acclimated

${ }_{1}^{1}$ Department of Forest Resources, University of Minnesota, Minnesota 55108, USA. ${ }^{2}$ Hawkesbury Institute for the Environment, Western Sydney University, Penrith, New South Wales 2753, Australia. ${ }^{3}$ State Key Laboratory of Soil Erosion and Dryland Farming on the Loess Plateau, Northwest A\&F University, Yangling 712100, China. ${ }^{4}$ Smithsonian Environmental Research Center, Edgewater, Maryland 20137, USA. 
(see Extended Data Fig. 1a, equivalent to homeostatic acclimation) ${ }^{7}$. If the rate after 3 weeks at $25^{\circ} \mathrm{C}$ had increased, but by less than $40 \%$ compared to the plant grown and measured at $20^{\circ} \mathrm{C}$, this would represent partial acclimation (Extended Data Fig. 1b). Thus, an acclimated plant will eliminate some or all of the increase in $R_{\text {leaf }}$ with rising temperature expected of non-acclimated plants.

We compare acclimation responses between experimental and natural seasonal temperature variation, boreal and temperate species, and angiosperm and gymnosperm species. On the basis of previous research $3,7,9-13,23,24$, we expected to observe partial acclimation (of $\sim 30-50 \%$ ) that would be similar across species in response to both experimental and temporal temperature variation. We also anticipated that boreal species, which experience a greater temperature range in their native higher-latitude distributions, would show a greater acclimation than temperate species.

Calculating entire respiratory temperature response curves (rather than measurements at a single temperature) for all sampled leaves enabled us to discern whether the shape of the shortterm response varies with thermal environment, or whether the elevation of the entire curve shifts over time as experienced temperatures vary. We tested five models to establish the best equation for quantifying $R_{\text {leaf }}$ as a function of short-term leaf temperature variation (see Methods). Across all 1,620 curves, all models provided good fits. Exponential equations with a fixed $Q_{10}$ coefficient (that describes the proportional change in $R_{\text {leaf }}$ with a $10^{\circ} \mathrm{C}$ temperature increase) and an Arrhenius model worked well (median $R^{2}=0.95$, Extended Data Table 1 ). By contrast, adding temperaturesensitivity did not improve the Arrhenius model, and two other temperature-sensitive models (a log-polynomial ${ }^{20}$ and a MichaelisMenton approach ${ }^{21}$ ) did not consistently show their expected decelerating forms (see Methods and Extended Data Table 1). Given that fits were best described as exponential, we present the data using the $Q_{10}$ approach; however, results are similar if any of the other models are used.

The $Q_{10}$ value differed among species, but was unaffected by experimental warming, as there were no differences in $Q_{10}$ across the warming treatments for any of the 10 species studied (Extended Data Fig. 2 and Table 1). Thus, to assess acclimation for each species, we compared $R_{\text {leaf }}$ at a standardized measurement temperature, which represents the overall elevation of each curve, given consistent $Q_{10}$ values. We chose standard leaf temperatures of $20^{\circ} \mathrm{C}$ and $23.4^{\circ} \mathrm{C}$, and derived respiration rates at those temperatures $\left(R_{20}\right.$ and $R_{23.4}$, respectively) for each temperature response curve. We chose $20^{\circ} \mathrm{C}$ as a typical standard for comparing respiration rates ${ }^{7,13,25}$, and $23.4^{\circ} \mathrm{C}$ because it represents the average temperature above that standard due to the warming treatment ${ }^{18,19,26}$.
We also assessed the acclimation response to seasonal variation in temperature by examining $R_{20}$ in relation to the mean night-time temperature for the 5 nights before the measurement date. We chose this rather than the previous 10 -day period ${ }^{4,16,17}$, as evidence suggests acclimation can occur within a few days of temperature shifts ${ }^{10,23,24}$, hence our response curves are perhaps more representative of leaf physiological status over the previous 5-day than 10-day period. Nonetheless, acclimation was similar (in fact, slightly stronger) if the previous 10-night mean temperature was used, and the results are not dependent on this choice.

Across species and sites, plants in the $+3.4^{\circ} \mathrm{C}$ treatment had significantly lower $R_{20}$ values than ambient-grown plants (Extended Data Fig. 3 and Table 1), indicating acclimation to increased growth temperature ${ }^{3,7}$. The best statistical model included only treatment and species (see Methods), as the response to warming treatment did not differ with site ( site $\times$ warming, $P=0.74$; site $\times$ species $\times$ warming, $P=0.69)$. Species differed in their average $R_{20}$ value, but the acclimation response to experimental warming did not differ significantly among species (Table 1), sites or species groupings (boreal/temperate; angiosperm/gymnosperm). Differences between ambient and warmed plants were similar if other metrics (for example, $R_{\text {leaf }}$ measured at $25^{\circ} \mathrm{C}$ ) were used, or if $R_{\text {leaf }}$ was estimated using temperature response functions from the alternative models (for example, Methods and Extended Data Figs 4 and 5).

As a result of this strong acclimation (Extended Data Fig. 3), individuals in each species grown in the $+3.4^{\circ} \mathrm{C}$ warming treatment had leaf respiration rates at $23.4^{\circ} \mathrm{C}$ that were generally not notably greater than those of ambient-grown plants measured at $20.0^{\circ} \mathrm{C}$ (Fig. 1). In fact, on average across species, plants grown in the $+3.4^{\circ} \mathrm{C}$ warming treatment had leaf respiration rates at $23.4^{\circ} \mathrm{C}$ that were just $5 \%$ higher $( \pm 2 \%$ s.e.m. among species) on average than those measured at $20.0^{\circ} \mathrm{C}$ for untreated plants (Fig. 2). By contrast, non-acclimated ambient-grown plants had rates at $23.4^{\circ} \mathrm{C}$ that were $23 \%$ higher $( \pm 1 \%$ s.e.m. among species $)$ on average than at $20.0^{\circ} \mathrm{C}$ (Figs 1 and 2). Thus, thermal acclimation of warmed plants eliminated roughly $80 \%$ of the increase in leaf respiration expected of non-acclimated plants (see below).

Shifts in $R_{20}$ in relation to seasonal variation in temperature (Fig. 3) also demonstrated strong acclimation that was consistent with shifts in $R_{20}$ in response to warming treatments. This acclimation was statistically examined by evaluating the $R_{20}$ response to prior 5-night mean temperature, warming treatment and species. The prior 5-night mean temperature was significant, whereas warming treatment was not, because the prior 5-night temperature metric fully accounted for its impact (Table 1). Thus, all 10 species showed pronounced acclimation of $R_{20}$ to recently experienced temperatures (Fig. 3). The slopes of $R_{20}$ versus recent temperatures did not differ between boreal and

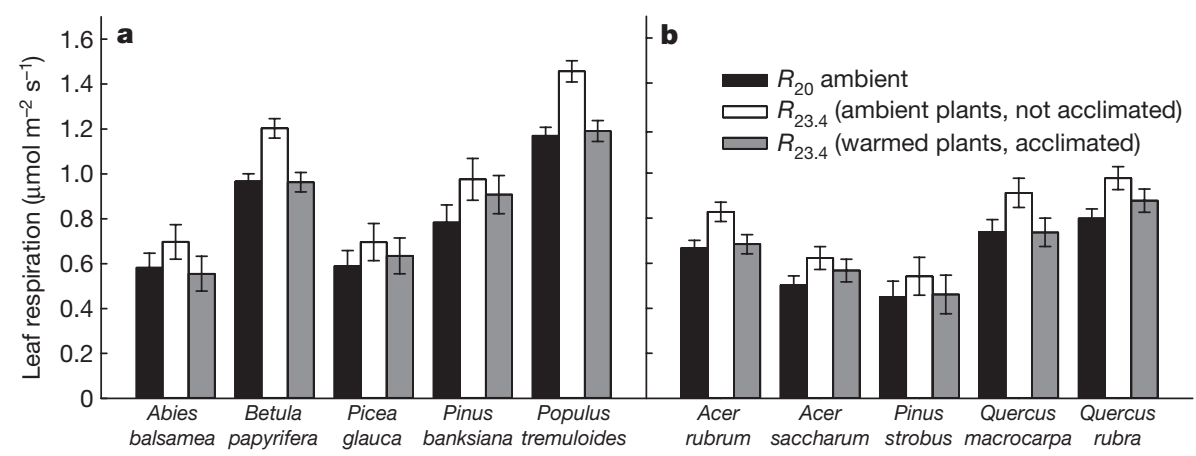

Figure 1 Leaf dark respiration rate of ambient and experimentally warmed plants. a, b, Data are from five boreal (a) and five temperate (b) tree species. Respiration is shown at measurement temperatures of $20^{\circ} \mathrm{C}$ and $23.4^{\circ} \mathrm{C}$ for ambient-grown plants; respiration for plants grown at $+3.4^{\circ} \mathrm{C}$ conditions is shown at a measurement temperature of $23.4^{\circ} \mathrm{C}$. The two values for ambient plants show the increase in respiration with a $+3.4^{\circ} \mathrm{C}$ temperature increase for non-acclimated plants; comparison of ambient plants measured at $20^{\circ} \mathrm{C}$ with warmed plants measured at $23.4^{\circ} \mathrm{C}$ represents the increase in respiration with a $+3.4^{\circ} \mathrm{C}$ temperature increase for acclimated plants. Sample size by warming treatment and biome type (boreal, ambient $=363$; boreal, warmed $=380$; temperate, ambient $=434$; temperate, warmed $=443$ ). Data are mean and s.e.m. (s.e.m. values are from the full model). 


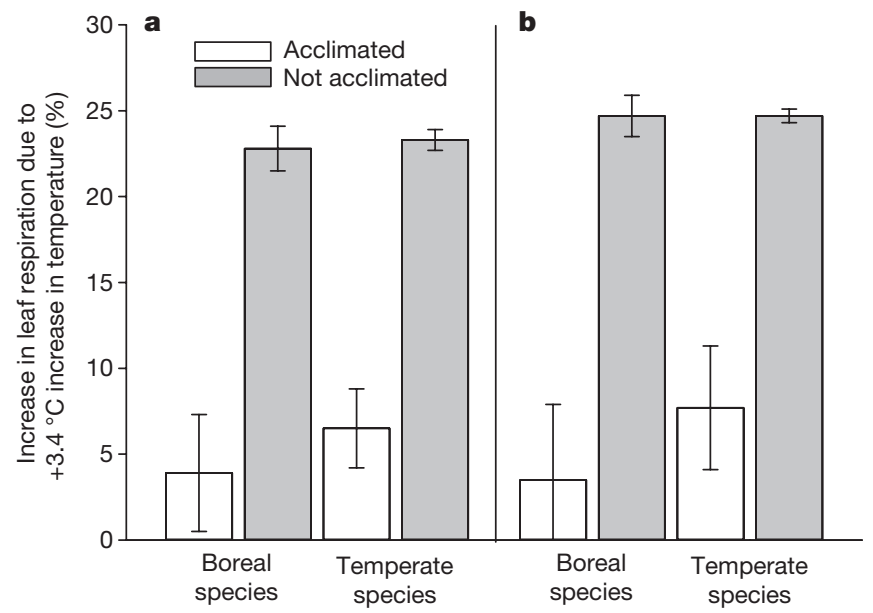

Figure $2 \mid$ Increase in leaf dark respiration $\left(R_{\text {leaf }}\right)$ with $+3.4^{\circ} \mathrm{C}$ warming for acclimated and non-acclimated plants, among species, by biome of the species. $\mathbf{a}, \mathbf{b}$, Increase in $R_{\text {leaf }}$ is shown on a percentage basis in response to both experimental warming (a) and seasonal temperature variation $(\mathbf{b})$. For acclimated plants, response is calculated as: $\left(\left(R_{\text {leaf }}\right.\right.$ of warmed plants at $23.4^{\circ} \mathrm{C}$ per $R_{\text {leaf }}$ of ambient plants at $\left.\left.20^{\circ} \mathrm{C}\right) \times 100\right)-100$. For non-acclimated plants, response is: $\left(\left(R_{\text {leaf }}\right.\right.$ of ambient plants at $23.4^{\circ} \mathrm{C}$ per $R_{\text {leaf }}$ of ambient plants at $\left.\left.20^{\circ} \mathrm{C}\right) \times 100\right)-100$. Sample sizes are as in Fig. 1. Data are mean and s.e.m. (s.e.m. among species, by biome group and treatment).

temperate species, but were significantly steeper on average for the four gymnosperms than the six angiosperms (Methods and Extended Data Table 2).

On the basis of the species responses to seasonal temperature variation, plants that had experienced recent night temperatures of $23.4^{\circ} \mathrm{C}$ would be expected to have $R_{\text {leaf }}$ at $23.4^{\circ} \mathrm{C}$ that was just $6 \%$ higher $( \pm 3 \%$ s.e.m. among species) on average than $R_{\text {leaf }}$ at $20.0^{\circ} \mathrm{C}$ for plants recently experiencing $20.0^{\circ} \mathrm{C}$ nights (Fig. 2). By contrast, without acclimation (that is, for a plant that recently experienced $20.0^{\circ} \mathrm{C}$ nights), rates at $23.4^{\circ} \mathrm{C}$ would be $25 \%$ ( $\pm 1 \%$ s.e.m. among species) higher on average than at $20.0^{\circ} \mathrm{C}$. Those acclimation responses to seasonal temperature variation were very similar to those noted above for plants acclimated to $+3.4^{\circ} \mathrm{C}$ experimental warming. In other words, the differences in growth temperatures due to experimental warming had the same effect on $R_{\text {leaf }}$ value at any given measurement temperature as the changes in the prior 5-night temperature of the same extent. Thus, acclimation to temperature as it varied across time was similar to acclimation to experimental warming. If extrapolated to a $10^{\circ} \mathrm{C}$ shift in temperature, acclimation would result in realized long-term (or 'apparent') $Q_{10}$ value of $\sim 1.2$, despite a short-term $Q_{10}$ of $\sim 1.9$.

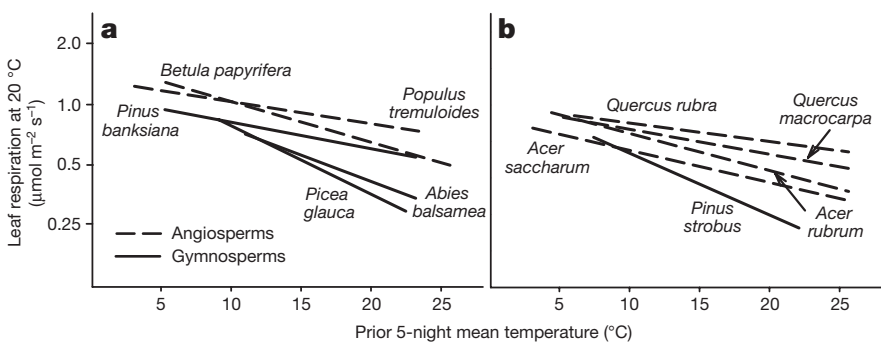

Figure 3 Relationship between leaf dark respiration measured at $20^{\circ} \mathrm{C}$ and the prior 5-night mean temperature, across seasons and years. a, b, Data are for five boreal (a) and five temperate (b) tree species. Sample sizes are as in Fig. 1. Data are the best fit regressions between the logarithm of $R_{20}$ and the prior 5-night mean temperature per species, using data from both ambient and warmed treatments. Angiosperms and gymnosperms differed in slope $(P<0.05)$, but species within each group did not. Resultant species-specific equations are shown in Extended Data Table 2 .
Table $1 \mid Q_{10}$ and $R_{20}$ in relation to $+3.4^{\circ} \mathrm{C}$ warming and species

\begin{tabular}{|c|c|c|c|c|c|c|}
\hline \multirow[t]{2}{*}{ Source of variance } & \multicolumn{2}{|r|}{$Q_{10}$} & \multicolumn{2}{|r|}{$R_{20}$} & \multicolumn{2}{|c|}{$R_{20}, 5$-night $T$} \\
\hline & $\bar{F}$ & $P>F$ & $F$ & $P>F$ & $F$ & $P>F$ \\
\hline Species & 4.66 & $<0.0001$ & 57.07 & $<0.0001$ & 40.89 & $<0.0001$ \\
\hline Treatment & 0.66 & 0.4199 & 11.53 & 0.0012 & 2.59 & 0.1119 \\
\hline Species $\times$ treatment & 1.09 & 0.3646 & 0.76 & 0.6557 & 1.17 & 0.3127 \\
\hline 5-night T & & & & & 38.95 & $<0.0001$ \\
\hline 5-night $T \times$ species & & & & & 2.48 & 0.0081 \\
\hline 5-night $T \times$ treatment & & & & & 0.01 & 0.9265 \\
\hline $\begin{array}{l}\text { 5-night } T \times \text { species } \times \\
\text { treatment }\end{array}$ & & & & & 0.34 & 0.9626 \\
\hline Full model $R^{2}$ & 0.10 & & 0.43 & & 0.45 & \\
\hline
\end{tabular}

We also assessed percentage acclimation, a measure of how much of the respiratory increase expected due to short-term (minutes to hours) warming is eliminated by physiological adjustment of plants warmed by the same extent but for weeks or months. We quantified this acclimation for plants in response to warming treatment by contrasting the difference between the $R_{23.4}$ of plants in the $+3.4^{\circ} \mathrm{C}$ treatment and the $R_{20}$ of those in ambient conditions with the difference between the $R_{23.4}$ and $R_{20}$ of plants in ambient conditions (Fig. 1; see Methods for equation). The mean percentage acclimation to experimental warming across species was $78.2 \%$ ( \pm 7.7 s.e.m. among species), and the mean percentage acclimation to the 5 -prior night temperature was $80.9 \pm 9.5 \%$ (Extended Data Fig. 6).

Given the close coupling of respiration and photosynthesis ${ }^{13,21,27,28}$, shifts in leaf respiration of plants growing under different thermal conditions could result from temperature-related shifts in photosynthesis ${ }^{14}$. Previous work with seedlings has found the ratio of leaf respiration to photosynthesis $(R: P)$ to be stable in some cases, but to increase with growth temperature in others ${ }^{14}$. Data from our multi-year experiment indicate that the acclimation of $R_{\text {leaf }}$ did not result from (or result in) a stable $R: P$ ratio, because for all 10 species, $R: P$ was higher in warmer conditions, whether seasonal or experimental (Methods). However, without acclimation, $R: P$ would have been much more increased at higher mean daily temperatures compared to what was observed. Hence our results suggest that acclimation is part of a process that limits the size of the 'window' within which $R: P$ varies, but does not support the idea of a complete homeostasis of $R: P$. Statistical analyses also showed that the response to warming treatment of $Q_{10}$, or $R_{20}$, could not be explained by concomitant shifts in photosynthesis (Methods).

As respiration in terrestrial plants (including root, stem and leaf fluxes) releases $\sim 64 \mathrm{Gt}$ of carbon per year to the atmosphere, offsetting $\sim 50 \%$ of terrestrial GPP ${ }^{5,6,16,17}$, autotrophic respiration and its acclimation to rising temperature are crucial to the global carbon balance ${ }^{5,6}$. Our experimental results are informative relative to this issue.

Our results demonstrated strong acclimation of leaf respiration to both a $+3.4^{\circ} \mathrm{C}$ warming and seasonal temperature increases, which profoundly reduced plant respiratory carbon loss compared to what would have occurred without acclimation. A recent meta-analysis ${ }^{7}$, based largely on short-term studies of laboratory grown plants, found acclimation to be less than half as great as we observed (see Methods for details). Moreover, earth system models ${ }^{14-17}$ typically simulate even weaker levels of acclimation, or none at all. For example, two recent modelling papers ${ }^{16,17}$ based their acclimation routines on data from first-year seedlings in laboratory settings that showed $30 \%$ respiration acclimation ${ }^{4}$. Despite this more modest acclimation than we observed here, acclimation alone still resulted in a $10 \%$ change in simulated global carbon stocks compared to a model that assumed no 
leaf respiration acclimation ${ }^{17}$. Given that we observed a much greater ( $\sim 80 \%)$ acclimation of respiration, our results suggest that high latitude forests may show a more pronounced leaf respiration acclimation than expected $^{4,7,13}$ to increasing growing season temperatures associated with climate change.

If our realistic, long-term field results are broadly indicative, they suggest that leaf respiratory acclimation globally may have a larger ameliorating impact than expected on $\mathrm{CO}_{2}$ losses with rising temperatures as climate changes. Such amelioration would be even larger if stems and roots showed similar acclimation as leaves, but whether this is so is highly uncertain owing to a scarcity of available data. Our results contribute to current efforts to improve the characterization and incorporation of thermal acclimation of respiration in land surface models ${ }^{14,17}$ by providing robust field evidence on the nature and magnitude of leaf respiratory acclimation, thus aiding future models in improving estimates of respiratory acclimation in a changing climate, and of the consequences of acclimation for carbon cycling.

Online Content Methods, along with any additional Extended Data display items and Source Data, are available in the online version of the paper; references unique to these sections appear only in the online paper.

\section{Received 7 September 2015; accepted 18 January 2016.} Published online 16 March 2016.

1. Cox, P. M., Betts, R. A., Jones, C. D., Spall, S. A. \& Totterdell, I. J. Acceleration of global warming due to carbon-cycle feedbacks in a coupled climate model. Nature 408, 184-187 (2000).

2. Heimann, M. \& Reichstein, M. Terrestrial ecosystem carbon dynamics and climate feedbacks. Nature 451, 289-292 (2008).

3. Atkin, O. K. \& Tjoelker, M. G. Thermal acclimation and the dynamic response of plant respiration to temperature. Trends Plant Sci. 8, 343-351 (2003).

4. Campbell, C. et al. Acclimation of photosynthesis and respiration is asynchronous in response to changes in temperature regardless of plant functional type. New Phytol. 176, 375-389 (2007)

5. Arneth, A. et al. Terrestrial biogeochemical feedbacks in the climate system. Nature Geosci. 3, 525-532 (2010).

6. Intergovernmental Panel on Climate Change. Climate Change 2013: The Physical Science Basis (Cambridge Univ. Press, 2013)

7. Slot, M. \& Kitajima, K. General patterns of acclimation of leaf respiration to warmer temperatures across biomes and plant types. Oecologia $\mathbf{1 7 7 , 8 8 5 - 9 0 0}$ (2015).

8. Luo, Y. Terrestrial carbon-cycle feedback to climate warming. Annu. Rev. Ecol. Evol. Syst. 38, 683-712 (2007).

9. Gunderson, C. A., Norby, R. J. \& Wullschleger, S. D. Acclimation of photosynthesis and respiration to simulated climatic warming in northern and southern populations of Acer saccharum: laboratory and field evidence. Tree Physiol. 20, 87-96 (2000).

10. Lee, T. D., Reich, P. B. \& Bolstad, P. V. Acclimation of leaf respiration to temperature is rapid and related to specific leaf area, soluble sugars and leaf nitrogen across three temperate deciduous tree species. Funct. Ecol. 19, 640-647 (2005).

11. Loveys, B. R. et al. Thermal acclimation of leaf and root respiration: an investigation comparing inherently fast- and slow-growing plant species. Glob. Change Biol. 9, 895-910 (2003).

12. Slot, M. et al. Thermal acclimation of leaf respiration of tropical trees and lianas: response to experimental canopy warming, and consequences for tropical forest carbon balance. Glob. Chang. Biol. 20, 2915-2926 (2014).

13. Tjoelker, M. G., Oleksyn, J., Reich, P. B. \& Zytkowiak, R. Coupling of respiration, nitrogen, and sugars underlies convergent temperature acclimation in Pinus banksiana across wide-ranging sites and populations. Glob. Change Biol. 14, 782-797 (2008).
14. Smith, N. G. \& Dukes, J. S. Plant respiration and photosynthesis in global-scale models: incorporating acclimation to temperature and $\mathrm{CO}_{2}$. Glob. Chang. Biol. 19, 45-63 (2013)

15. Atkin, O. K., Meir, P. \& Turnbull, M. H. Improving representation of leaf respiration in large-scale predictive climate-vegetation models. New Phytol. 202, 743-748 (2014).

16. Smith, N. G. et al. Foliar temperature acclimation reduces simulated carbon sensitivity to climate. Nature Clim. Change http://dx.doi.org/10.1038/ nclimate2878 (2016).

17. Lombardozzi, D. L. et al. Temperature acclimation of photosynthesis and respiration: A key uncertainty in the carbon cycle-climate feedback. Geophys. Res. Lett. 42, 8624-8631 (2015).

18. Reich, P. B. et al. Geographic range predicts photosynthetic and growth response to warming in co-occurring tree species. Nature Clim. Change $\mathbf{5}$, 148-152 (2015)

19. Rich, R. L. et al. Design and performance of combined infrared canopy and belowground warming in the B4WarmED (Boreal Forest Warming at an Ecotone in Danger) experiment. Glob. Chang. Biol. 21, 2334-2348 (2015).

20. O'Sullivan, O. S. et al. High-resolution temperature responses of leaf respiration in snow gum (Eucalyptus pauciflora) reveal high-temperature limits to respiratory function. Plant Cell Environ. 36, 1268-1284 (2013).

21. Kruse, J., Rennenberg, H. \& Adams, M. A. Steps towards a mechanistic understanding of respiratory temperature responses. New Phytol. 189, 659-677 (2011)

22. Tjoelker, M. G., Oleksyn, J. \& Reich, P. B. Modelling respiration of vegetation: evidence for a general temperature-dependent $\mathrm{Q}_{10}$. Glob. Change Biol. 7, 223-230 (2001)

23. Atkin, O. K., Holly, C. \& Ball, M. C. Acclimation of snow gum (Eucalyptus pauciflora) leaf respiration to seasonal and diurnal variations in temperature: the importance of changes in the capacity and temperature sensitivity of respiration. Plant Cell Environ. 23, 15-26 (2000).

24. Bolstad, P. V., Reich, P. B. \& Lee, T. D. Rapid temperature acclimation of leaf respiration rates in Quercus alba and Quercus rubra. Tree Physiol. 23, 969-976 (2003).

25. Reich, P. B. et al. Scaling of respiration to nitrogen in leaves, stems, and roots of higher land plants. Ecol. Lett. 11, 793-801 (2008).

26. Sendall, K. M. et al. Acclimation of photosynthetic temperature optima of temperate and boreal tree species in response to experimental warming. Glob. Chang. Biol. 21, 1342-1357 (2015).

27. Katja, H. et al. Temperature responses of dark respiration in relation to leaf sugar concentration. Physiol. Plant. 144, 320-334 (2012).

28. Ow, L. F., Griffin, K. L., Whitehead, D., Walcroft, A. S. \& Turnbull, M. H. Thermal acclimation of leaf respiration but not photosynthesis in Populus deltoides $\times$ nigra. New Phytol. 178, 123-134 (2008).

Acknowledgements This research was supported by the US Department of Energy, Office of Science, Office of Biological and Environmental Research award DE-FG02-07ER64456; Minnesota Agricultural Experiment Station MIN-42-030 and MIN-42-060; the Minnesota Department of Natural Resources; and the College of Food, Agricultural, and Natural Resources Sciences and Wilderness Research Foundation, University of Minnesota. Assistance with experimental operation and data collection was provided by K. Rice, C. Buschena, C. Zhao, H. Jihua and numerous summer interns.

Author Contributions P.B.R., R.A.M. and R.L.R. designed the study. R.L.R designed the warming system. R.L.R. and A.S. implemented the warming system and A.S., K.M.S. and X.W. the day-to-day field measurements. P.B.R. analysed the data. P.B.R. wrote the first draft and along with the other co-authors jointly wrote the manuscript.

Author Information Reprints and permissions information is available at www.nature.com/reprints. The authors declare no competing financial interests. Readers are welcome to comment on the online version of the paper. Correspondence and requests for materials should be addressed to P.R. (preich@umn.edu). 


\section{METHODS}

Site description and experimental design. This study was conducted in an openair climate change facility (the Boreal Forest Warming at an Ecotone in Danger (B4WarmED) project) in northern Minnesota, USA. The details of the study sites and experimental design are described elsewhere ${ }^{18,19,26}$. The experiment used here had a 2 (site) $\times 2$ (habitat) $\times 2$ (warming treatment) factorial design with six replicates, for a total of 48 circular plots $3-\mathrm{m}$ in diameter. We sampled juveniles of 10 native tree species from the 11 per species planted into each plot in 2008 into a matrix of native shrubs and herbs. The treatments were ambient versus $+3.4^{\circ} \mathrm{C}$ above ambient (both below and above ground) and were implemented $24 \mathrm{~h}$ per day for 8-9 months per year ${ }^{19}$.

Measurement of leaf respiration temperature response curve and data analysis overview. Temperature response curves $(1,620)$ of leaf respiration were measured at both field sites from June-September each year and across the years 2009-2013. Measurements were made using detached foliage sampled from ambient and warmed plots ${ }^{26}$. Respiration temperature response curves were developed based on measurements at $12,17,22,27,32$ and $37^{\circ} \mathrm{C}$. Dark respiration rates of detached leaves are stable under these conditions for several hours or longer ${ }^{12,24}$.

Comparisons among five models showed that fixed $Q_{10}$ and Arrhenius models provided the most reasonable statistical approach for fitting short-term respiration-temperature response curves; moreover, the fixed $Q_{10}$ and Arrhenius models yielded virtually identical predictions, $R^{2}>0.99$ (see Extended Data Table 1 and Extended Data Figs 7 and 8 for more details). We therefore report only the following parameters: the $Q_{10}$ of the temperature response function of each leaf, and the respiration rate at standard measurement temperatures of $20.0^{\circ} \mathrm{C}$ $\left(R_{20}\right)$ and $23.4^{\circ} \mathrm{C}\left(R_{23.4}\right)$, calculated from the temperature response equation for every leaf.

The $R_{T}$ was calculated as:

$$
R_{T}=R_{T_{\text {ref }} Q_{10}}\left(\frac{T-T_{\text {ref }}}{10}\right)
$$

in which $R_{T}$ is the dark respiration measured at leaf temperature $T, R_{T_{\text {ref }}}$ is the respiration at reference temperature $T_{\text {ref }}$, and $Q_{10}$ is a metric that describes the proportional increase of respiration rate with a $10^{\circ} \mathrm{C}$ increase in temperature.

We calculated respiration rates at measurement temperatures of 20.0 and $23.4^{\circ} \mathrm{C}$ for both ambient and experimentally warmed treatments $\left(R_{20}\right.$ ambient, $R_{23.4}$ ambient and $R_{23.4 \text { warmed }}$ ) using equation (1). We chose to show values at measurement temperatures of 20 and $23.4^{\circ} \mathrm{C}$ as they represent a temperature $\left(20^{\circ} \mathrm{C}\right)$ that has been commonly used in other studies, and a temperature $\left(23.4^{\circ} \mathrm{C}\right)$ representing the difference due to our warming treatment. These were used in statistical analyses and to calculate percentage acclimation.

Mixed-effect analyses of variance were conducted to compare $Q_{10}$ and $R_{20}$ values across species, warming treatment, and sites. $R_{20}$ was log-transformed for statistical analyses to meet assumptions of normality and heteroscedasticity of residuals better. Comprehensive sampling of three of the species across warming treatments, sites, years, seasons and habitat, found minimal difference in acclimation response to warming among sites, years, seasons (early, mid or late summer) or habitat (X.W. et al., manuscript in preparation); hence here we focus on species, sites and treatments. The independent variables included in the initial models that tested for warming treatment effects were site, treatment and species (with plot considered a random effect). On the basis of both Akaike and Bayesian information criteria, the best models for $Q_{10}$ and $R_{20}$ included only treatment and species (moreover, response to warming did not differ among sites). We then tested for response to prior 5-night temperature, warming treatment and species. Including the prior 5-night mean temperature in the model was significant for $R_{20}$ but not significant for $Q_{10}$. Furthermore, after including prior 5-night temperature in the model, warming treatment was no longer significant (indicating that incorporating this effect into the prior 5-night temperature accounted for its effect), and the best model included only 5-night mean temperature and species.

To assess effect of acclimation on reducing expected respiratory carbon loss, we calculated percentage acclimation as:

$$
\text { Acclimation }(\%)=\frac{R_{23.4 \text { ambient }}-R_{23.4 \text { warmed }}}{R_{23.4 \text { ambient }}-R_{20.0 \text { ambient }}} \times 100
$$

in which a value of $<0$ means no acclimation, a value between 0 and $100 \%$ means partial acclimation, $100 \%$ means complete acclimation, $>100 \%$ means overacclimation.

Study sites. The B4WarmED experiment was conducted at the Cloquet Forestry Center at Cloquet, Minnesota, USA $\left(46^{\circ} 31^{\prime} \mathrm{N}, 92^{\circ} 30^{\prime} \mathrm{W}\right)$ and at the Hubachek
Wilderness Research Center near Ely, Minnesota, USA $\left(47^{\circ} 55^{\prime} \mathrm{N}, 92^{\circ} 30^{\prime} \mathrm{W}\right)$. Both sites are located in the boreal-temperate forest ecotone. The mean annual precipitation and temperature (1973-2008) were $783 \mathrm{~mm}$ and $4.8^{\circ} \mathrm{C}$ at Cloquet Forestry Center, and $726 \mathrm{~mm}$ and $2.6^{\circ} \mathrm{C}$ at the nearest weather stations to Hubachek Wilderness Research Center. The warming experiments at both sites were conducted on coarse-textured upland soils in mixed Populus tremuloides-Betula papyrifera-Abies balsamea stands (with stand ages of 40-60 years) in both understory (5-10\% full light) and open ( $40-60 \%$ full light) conditions, which are representative of the typical regeneration sites for the study species.

Experimental design. For details of experimental design, see refs 18, 19, 26. The treatments included two levels of simultaneous plant and soil warming (ambient temperatures and day and night temperatures $3.4^{\circ} \mathrm{C}$ above ambient throughout the entire growing season). Both treatments included soil heating cables (unelectrified cables in the ambient plots). The heating treatment was implemented during the 2009-2013 growing seasons with a synchronized above- and below-ground openair system (that is, without chambers) via feedback controls that acted concurrently and independently at the plot scale to maintain a fixed temperature differential from ambient conditions (see ref. 19 for a detailed description of the experimental warming system). Although warming treatments varied slightly with site, canopy and year ${ }^{19}$, on average $3.4^{\circ} \mathrm{C}$ warming of both above-ground plant surfaces and soil was obtained during treatments. Eleven individual seedlings of ten native species (most two years old and grown from local seed sources) were planted in each plot in 2008. The seedlings were obtained from the Minnesota Department of Natural Resources $^{18,26}$.

Measurement of leaf respiration temperature response curve details. The temperature response curves of leaf respiration were measured on detached foliage sampled from the ambient and warmed plots from June-September 2009-2013 (day of year $=169-271$ ). Sampling across the warming treatments was very closely balanced for each species across sites and habitats. Fully expanded, healthy leaves were collected each morning and were immediately inserted into floral water pik tubes to keep them hydrated throughout the day. The leaves were then transported to a nearby laboratory and transferred to a darkened growth chamber that was able to maintain a broad range of temperatures. Temperature response curves were measured from 12 to $37^{\circ} \mathrm{C}$ leaf temperature at increments of $\sim 5^{\circ} \mathrm{C}$ by adjusting the air temperatures of the growth chamber and the temperature control setting of the cuvette housing the sample leaf.

The dark respiration rate was measured using an infrared gas analyser system (LI-6400 portable photosynthesis systems, Li-Cor) with a standard $2 \times 3-\mathrm{cm}$ leaf chamber used for broadleafed species and a conifer chamber (that fits sprigs $7.5-\mathrm{cm}$ long with needles up to $3.5-\mathrm{cm}$ long) for the needle-leafed species, operated in an open configuration with a flow rate of $300-500 \mu \mathrm{mol} \mathrm{s}^{-1}$ and a $\mathrm{CO}_{2}$ concentration of $400 \mathrm{~mol} \mathrm{~mol}^{-1}$. The leaf chamber was placed inside the growth chamber, and the leaf temperature in the cuvette was set to correspond to the temperature in the growth chamber. The leaf was allowed to stabilize at the new temperature for a minimum of 10 min prior to being clamped in the leaf chamber for the dark respiration measurement. Three values were logged at $15 \mathrm{~s}$ intervals after the readings had stabilized and were averaged for each temperature. Dark respiration rates were measured for each leaf at $12^{\circ} \mathrm{C}$ control setting, after which both the leaf and growth chambers were set to $17^{\circ} \mathrm{C}$, and the process was repeated for all temperatures in increasing order. We note that the measurement of leaf temperature when the respiration measurement was made was recorded and used in all calculations, rather than the set point temperature (which was usually close, but not identical, to the measured leaf temperature). The humidity within the leaf chamber was controlled to the extent possible (see ref. 26 for details of controlling humidity in leaf chambers). The measurements were completed within 3-4h. Detailed measurements for three species across seasons (late spring, summer, early autumn), habitats and sites, showed that both the $Q_{10}$ of the short-term response curve and the acclimation of the entire curve to warming treatment effects were unaffected by habitat or site (X.W. et al., manuscript in preparation). Hence we focus here on species and treatment effects initially, and then on response to recently experienced temperatures.

An important question about measurements of dark respiration temperature response functions involves the stability of measurements over the time needed to conduct each curve. Although it has been shown that metabolism of sugars can change respiration rates ${ }^{13,27}$, extensive previous work done to test the stability of measurements with many of the same species as in our study has shown no effect of duration in the dark on respiration rates or their short-term temperature sensitivity ${ }^{10,12,13,27-29}$. Another recent study with a different tree species ${ }^{20}$, found that respiration rates and temperature responses were stable for as long as 4 days (the longest period they tested). As noted ${ }^{27}$, sugar concentrations found naturally had only a small effect on respiration of Populus leaves compared to those induced in artificially sucrose-fed leaves, and even in the latter, sugar concentration only had marked effects on respiration rates at leaf temperatures greater than $40^{\circ} \mathrm{C}$ and 
none detectable below $30^{\circ} \mathrm{C}$. Moreover, given that all treatments and species in our study received the same protocol it is unlikely that variability due to lack of stability influenced the outcome of our measurements and analyses.

Different approaches to fitting leaf respiration temperature response function. It has been known for decades that over the short-term (minutes to hours), respiration increases approximately exponentially with temperature (equivalent to loglinearly) $)^{3,7,20,21}$, which often can be well described by $Q_{10}$ or Arrhenius functions (see equations (1) and (3), and Extended Data Fig. 6). Hence both the $Q_{10}$ (equation (1)) and Arrhenius functions (equation (3)) have been widely used to describe the respiration-temperature response curves in plant, ecosystem, land surface, and earth system simulation models. However, several studies have reported the response to not be a fixed proportional change (on a logarithmic basis), but a decelerating proportional change $e^{20,22}$, such that if one uses the $Q_{10}$ approach to characterize this, the $Q_{10}$ is lower across any given temperature span at higher than lower temperatures ${ }^{20,22}$. In fact, the two most comprehensive assessments, one a synthesis by Tjoelker and colleagues ${ }^{22}$ and the other a new study of 218 species globally ${ }^{30}$ strongly support the temperature sensitive $Q_{10}$ model (that is, decelerating polynomial function). In such cases a temperature-sensitive Arrhenius (equation (4)) a polynomial model (equation (5)), with a value of $c<0$; and a Michaelis-Menton model (equation (6)), with a value of $\delta\left(T_{\text {ref }}\right)<0$ have been found to be good models to describe the observations. However, no single function has emerged as the best across all studies; thus, the nature and variability among taxa of the short-term temperature response function of leaf respiration remains uncertain ${ }^{3,4,14,20-22}$.

Given this uncertainty, we examined the alternative approaches with our data, and used the results to inform our choice of which to focus on. We examined five models $(1,3,4,5$ and 6$)$ :

$$
\begin{gathered}
R_{T}=R_{T_{\mathrm{ref}}} e^{\left[\frac{E_{a}}{r T_{\mathrm{ref}}}\left(1-\frac{T_{\mathrm{ref}}}{T}\right)\right]} \\
R_{T}=R_{T_{\mathrm{ref}}} e^{E_{a}\left(\frac{T_{\mathrm{ref}}}{T_{\mathrm{ref}}-T_{0}}-\frac{T_{\mathrm{ref}}}{T-T_{0}}\right)} \\
R_{T}=e^{a+b T+c T^{2}} \\
\ln R_{T}=\ln R_{T_{\mathrm{ref}}}+\frac{E_{0}\left(T_{\mathrm{ref}}\right)}{r} \times \frac{\left[T-T_{\mathrm{ref}}\right]}{T\left(T_{\mathrm{ref}}\right)}+\delta\left(T_{\mathrm{ref}}\right)\left[\frac{T-T_{\mathrm{ref}}}{T\left(T_{\mathrm{ref}}\right)}\right]^{2}
\end{gathered}
$$

in which $R_{T}$ is the dark respiration measured at leaf temperature $T ; R_{T_{\mathrm{ref}}}$ is the respiration at reference temperature $T_{\text {ref, }} Q_{10}$ is a metric that describes the proportional increase of respiration rate with a $10^{\circ} \mathrm{C}$ increase in temperature; $E_{a}\left(\mathrm{~J} \mathrm{~mol}^{-1}\right)$ is the activation energy of respiration; $r$ is the universal gas constant $\left(8.314 \mathrm{~J} \mathrm{~mol}^{-1} \mathrm{~K}^{-1}\right) ; a, b$ and $c$ in equation (5) are coefficients that describe the temperature response of the natural log of respiration, and $E_{0}\left(T_{\text {ref }}\right)\left(\mathrm{J} \mathrm{mol}^{-1}\right)$ is the overall activation energy of the reference temperature. $T$ and $T_{\text {ref }}$ are in ${ }^{\circ} \mathrm{C}$ in equations (1) and (5), and in $\mathrm{K}$ in equation (3) and (4). A temperature-dependent $Q_{10}$ value can be calculated from parameters in equation $(5)^{20,22}$

$$
Q_{10}=e^{10 \times(T+2 c T)}
$$

A value of $c<0$ in equation (5) or $\delta\left(T_{\text {ref }}\right)<0$ in equation (6) indicates a decrease in $Q_{10}$ or $E_{0}$, respectively (each of which can be evaluated at every point along the curve) with temperature, and a value of $>0$ indicates an increase in $Q_{10}$ or $E_{0}$ with temperature, respectively.

Curves were considered for analysis only when all points fit within a $95 \%$ confidence interval, the $R^{2}$ exceeded 0.60 and the overall curve and slope parameters were at least marginally significant at $P<0.10$ for at least three of the models. In total, 1,620 curves met these requirements, with mean and median (across all curves and all five models) $R^{2}$ of 0.94 and 0.96 , respectively and with $99 \%$ significant at $P<0.05$. Given that curves on average were approximately exponential, the temperature-sensitive Arrhenius model (equation (4)) fit similarly well as, but very slightly less well than the Arrhenius model (equation (3)) and is not further discussed. Among the five equations (1), (3), (4), (5) and (6), equations (5) and (6) had a slightly higher $R^{2}$ and lower root mean square error (r.m.s.e.) values than equations (1) and (2) (Extended Data Table 1). However, among our 1,620 curves determined using equation (5), $894(55 \%)$ had $c<0$ and $726(45 \%)$ had $c>0$ (Extended Data Fig. 7), with roughly half of the curves for equation (6) also not supporting a decelerating function. Thus, for our sample, an accelerating proportional change in respiration was almost as likely as a decelerating proportional change, refuting the idea that a decelerating model is a good choice overall for our data. Given that use of either equation (5) or (6) is inconsistent with any single shape of the response function, including the deceleration framework that is the underlying premise of both models, we did not use either to describe our measured response curves. Instead equations (1) and (3) ( $Q_{10}$ and Arrhenius models) performed similarly and very well; they had similar $R^{2}$ and r.m.s.e. values (Extended Data Table 1), and were roughly equally accurate across the full range of measurement temperatures. Moreover, the predicted respiration rates from equations (1) $\left(Q_{10}\right)$ and (3) (Arrhenius function) at the reference temperature of $20^{\circ} \mathrm{C}$ were nearly identical (data not shown), and as expected, $Q_{10}$ from equation (1) was extremely well correlated $\left(R^{2}=0.999\right)$ with $E_{a}$ from equation (3) (Extended Data Fig. 6). For the respiration data generated in our study, using the exponential fit was a reasonable statistical approach, and we therefore only report parameters from equation (1); but do not intend this as an indication that equation (1) is preferable to equation (3) for these data. We note the estimates of acclimation would be similar regardless of which of the five models of short-term respiration response were used.

Statistical tests. To compare leaf respiration rates across species, warming treatments, and recently experienced night-time temperatures, we converted the respiration rates of all leaves to values at a common measurement temperature of $20^{\circ} \mathrm{C}$ $\left(R_{20}\right)$, using the leaf-specific equation (1) for each of the 1,620 leaves. To assess how much of the potential increase in respiration the acclimation eliminates, we calculated percentage acclimation using equation (2), where a value of $<0$ means no acclimation, a value between 0 and $100 \%$ means partial acclimation, $100 \%$ means complete acclimation, $>100 \%$ means over acclimation. We also expressed $R$ at $25^{\circ} \mathrm{C}\left(R_{25}\right)$ to test for many of the relationships described in this paper using $R_{20}$, including those with photosynthesis, as $25^{\circ} \mathrm{C}$ was in the centre of the temperature range used to develop the response curve for each leaf and $R$ at $25^{\circ} \mathrm{C}$ is perhaps the most common reference value ${ }^{31}$.

Mixed-effect analyses of variance were conducted to compare $Q_{10}, R_{20}$ and $R_{25}$ data by species, site and treatment, pooled across all other sources of variation. $R_{20}$ and $R_{25}$ were log-transformed to fit assumptions of a normal distribution. As responses of $R_{25}$ and $R_{20}$ were extremely similar, we largely show only those for the latter here. We also fit simple regressions of $\log \left(R_{20}\right)$ versus prior 5-night and 10-night temperatures, for each species, and used these to calculate percentage acclimation across time. All data analyses used JMP 11.0 (SAS Institute).

Model selection and results. We first tested models for $Q_{10}$ and $R_{20}$ including species, site, warming treatment and all interactions (with plot included as a random effect). There were no site $\times$ treatment (or site $\times$ treatment $\times$ species) interactions, nor was site (with or without interactions) included in the best models (based on both on AIC and BIC criteria), hence site was not considered further in any models. The best models included only treatment and species (both significant as main effects), but we show the model including their interaction term in Table 1 to allow readers to see the level of significance of their interaction. We also tested whether grouping species by biome of origin (boreal versus temperate) or phylogenetic group (angiosperm versus gymnosperm), instead of by species, identified a difference in response to warming treatment by groups. Group was significant in both cases as a main effect, but there was no significant interaction with treatment and the models were much poorer overall than those including species (data not shown).

We also tested an additional model for $R_{20}$ that included the prior temperature (temperature of the prior 5 nights) and all interactions (shown in Table 1). Species, prior temperature and the interaction of species $\times$ prior temperature were the only significant terms. However the species $\times$ prior temperature interaction was only significant for the species with the steepest and shallowest slopes (Picea glauca and Quercus macrocarpa, respectively), and neither of those species had a slope significantly different than any other species from the same phylogenetic group (gymnosperm or angiosperm). Thus we tested the model for $R_{20}$ with independent predictors of phylogenetic group, prior temperature and their interaction. Groups differed in slope $(P=0.0084)$ of $R_{20}$ to prior 5 -night temperature. Models for each group separately found species did not differ in slope (no species $\times 5$-night temperature interaction) but did differ in intercept (species significant as main effect). Thus, for modelling purposes the most statistically appropriate equations are for each species to have a unique intercept, but for all gymnosperms and angiosperms to share a common slope (Extended Data Table 2), as derived from separate models for conifers $\left(R^{2}=0.33\right.$ for model) and angiosperms $\left(R^{2}=0.27\right.$ for model $)$.

Furthermore, as autotrophic respiration is a process closely coupled to photosynthesis $^{13,21,27}$, shifts in leaf respiration observed for plants growing under different thermal conditions could result from the coupling of respiration and photosynthesis, and temperature related shifts in photosynthesis ${ }^{14}$. If this were the case, acclimation of leaf respiration might be driven largely by temperaturerelated variation in photosynthesis. Empirical evidence from prior publications, predominantly for laboratory grown seedlings, found that the ratio of leaf respiration to photosynthesis $(R: P)$ was stable in some cases, but increased with growth 
temperature in others ${ }^{14}$. Using temperature response curves of photosynthesis made in this experiment ${ }^{26}$, we estimated photosynthesis at prevailing daytime temperatures and combined these with estimates of leaf respiration at prevailing night-time temperatures to estimate the $R: P$ ratio and assess how it varied with temperature (using mean daily 24 -h temperature to represent the general thermal regime). These estimates indicate that acclimation of $R_{\text {leaf }}$ did not result from (or result in) a stable $R: P$ ratio, because for all 10 species, $R: P$ was higher in warmer conditions, whether seasonal or experimental. However, the acclimation of leaf respiration did constrain the extent to which $R: P$ varies, because without acclimation, $R: P$ would have been much more increased at higher mean daily temperatures compared to what was observed. Hence our results are consistent with the notion that acclimation is part of a process that limits the size of the 'window' within which $R: P$ varies, but does not support the idea of a complete homeostasis of $R: P$ that would directly result in acclimation of leaf respiration, if photosynthesis rose little with increased temperatures.

We also assessed whether the response to warming treatment of $Q_{10}$, or leaf respiration rate at a given measurement temperature, could be explained in full or part by photosynthesis. We did this by including photosynthesis as a predictor in models that examined (1) $Q_{10}$, and (2) respiration at $20^{\circ} \mathrm{C}\left(R_{20}\right)$ or $25^{\circ} \mathrm{C}\left(R_{25}\right)$, in relation to species, treatment, and the species $\times$ treatment interaction (across all 1,620 leaves). As elsewhere, $R_{20}$ and $R_{25}$ were log-transformed to fit assumptions of a normal distribution. Including photosynthesis in these analyses did not alter our results or conclusions. In the model with $Q_{10}$ as the dependent variable, photosynthesis was not significant $(P=0.62)$, nor was warming treatment $(P=0.78)$, but species was $(P=0.0025)$, and $Q_{10}$ values for each species in both ambient and warmed treatments were similar as our original analyses. In the models with $R_{20}$ and $R_{25}$ as the dependent variables, photosynthesis was significant $(P<0.0001)$, (that is, respiration was positively related to photosynthetic rate), and the temperature treatment remained significant $(P=0.05)$, with the degree of shift of respiration with warming treatment (that is, the acclimation) similar with or without photosynthesis in the model.

Comparison with published acclimation meta-analysis. A recent meta-analysis on acclimation of leaf respiration to temperature ${ }^{7}$ provides a useful basis of comparison for our work. Among 104 records for 67 species from 18 studies, 96 were from growth cabinets or greenhouses, with an average duration of 41 days and a wide range of the degree of warming. This meta-analysis includes the data from ref. 4 that is the basis for several recent assessments of acclimation effects on global carbon cycling. On average across all records, the increase in $R_{\text {leaf }}$ for a onedegree temperature increase was $5.7 \%$ for that meta-analysis ${ }^{7}$, compared with $1.5 \%$ from the 10 species in our study. In the meta-analysis, the response of $R_{\text {leaf }}$ per ${ }^{\circ} \mathrm{C}$ increase was weakly but significantly linearly correlated with the degree of warming $\left(R^{2}=0.04, P=0.036\right)$, suggesting that the extent of acclimation is less when the shift in temperature is greatest. On the basis of that correlation, acclimation in response to $3.4^{\circ} \mathrm{C}$ warming should result in a $3.4 \%$ increase in $R_{\text {leaf }}$ per ${ }^{\circ} \mathrm{C}$. Hence, both the mean shift in $R_{\text {leaf }}$ across all data $\left(+5.7 \%\right.$ per ${ }^{\circ} \mathrm{C}$ warming $)$ and the shift after adjustment to a $+3.4^{\circ} \mathrm{C}$ warming $\left(+3.4 \%\right.$ per ${ }^{\circ} \mathrm{C}$ warming $)$ from the meta-analysis are at least twice as great as the increase in $R_{\text {leaf }}\left(1.5 \%\right.$ per ${ }^{\circ} \mathrm{C}$ warming) from our study. There are several potential reasons why acclimation was so much stronger in our study than in previous studies; these include the longer duration of the treatments and the more realistic whole-plant warming treatments, among others.

29. Mitchell, K. A., Bolstad, P. V. \& Vose, J. M. Interspecific and environmentally induced variation in foliar dark respiration among eighteen southeastern deciduous tree species. Tree Physiol. 19, 861-870 (1999).

30. Heskel, M. A. et al. Convergence in the temperature response of leaf respiration across biomes and plant functional types. Proc. Natl Acad. Sci. (in press).

31. Atkin, O. K. Global variability in leaf respiration in relation to climate, plant functional types and leaf traits. New Phytol. 206, 614-636 (2015). 


\section{RESEARCH LETTER}

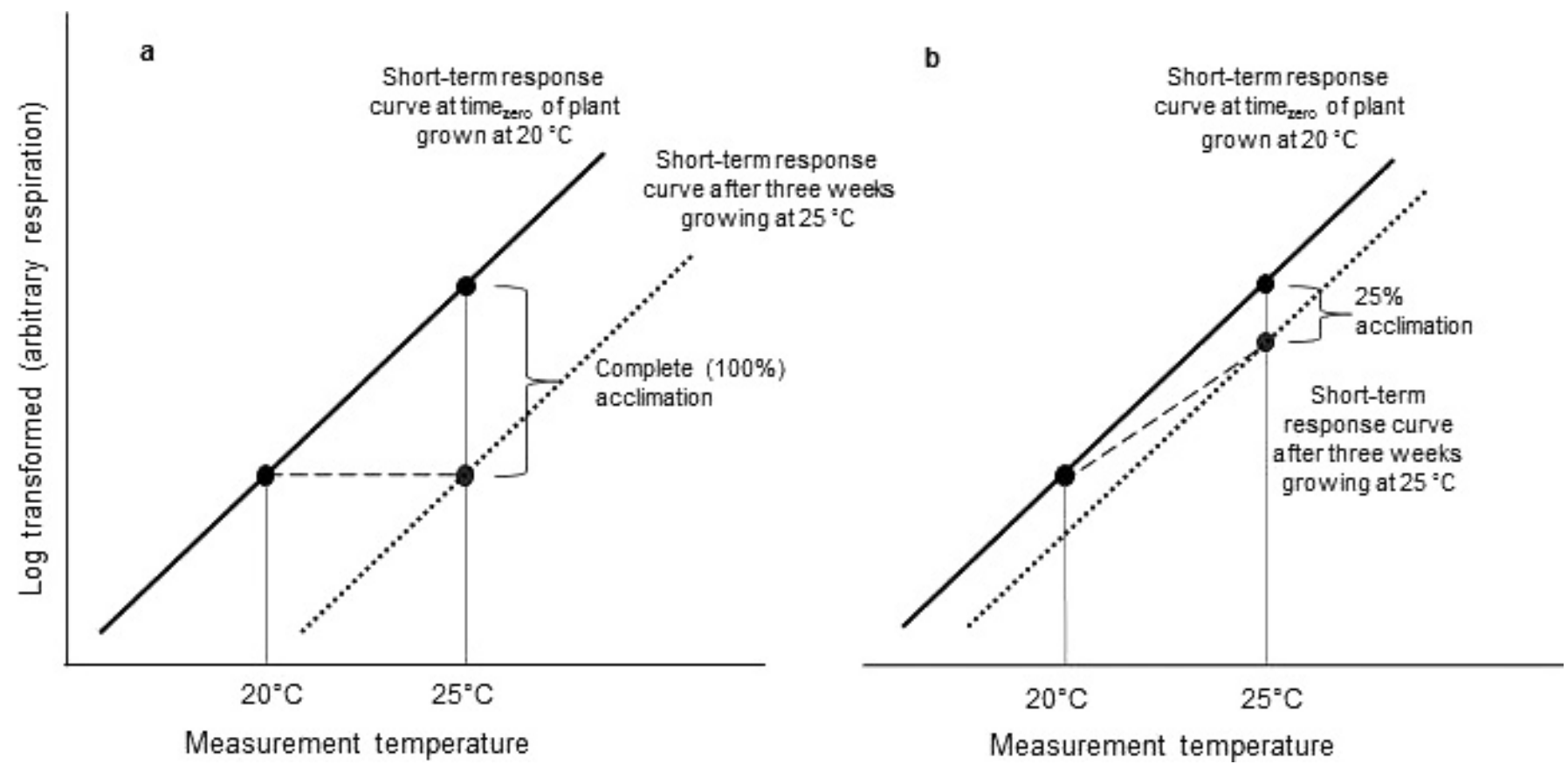

Extended Data Figure 1 | Illustration of complete and partial acclimation. a, If a plant increased respiration by $40 \%$ when placed under conditions $5^{\circ} \mathrm{C}$ warmer for $30 \mathrm{~min}$ (solid line), but had no increase

after 3 weeks at the same $+5^{\circ} \mathrm{C}$ conditions (dotted line), it would have completely acclimated. b. If the increase over 3 weeks was $30 \%$, it would have partially acclimated by $25 \%$ (dotted lined), and so on. 
Boreal species

Temperate species

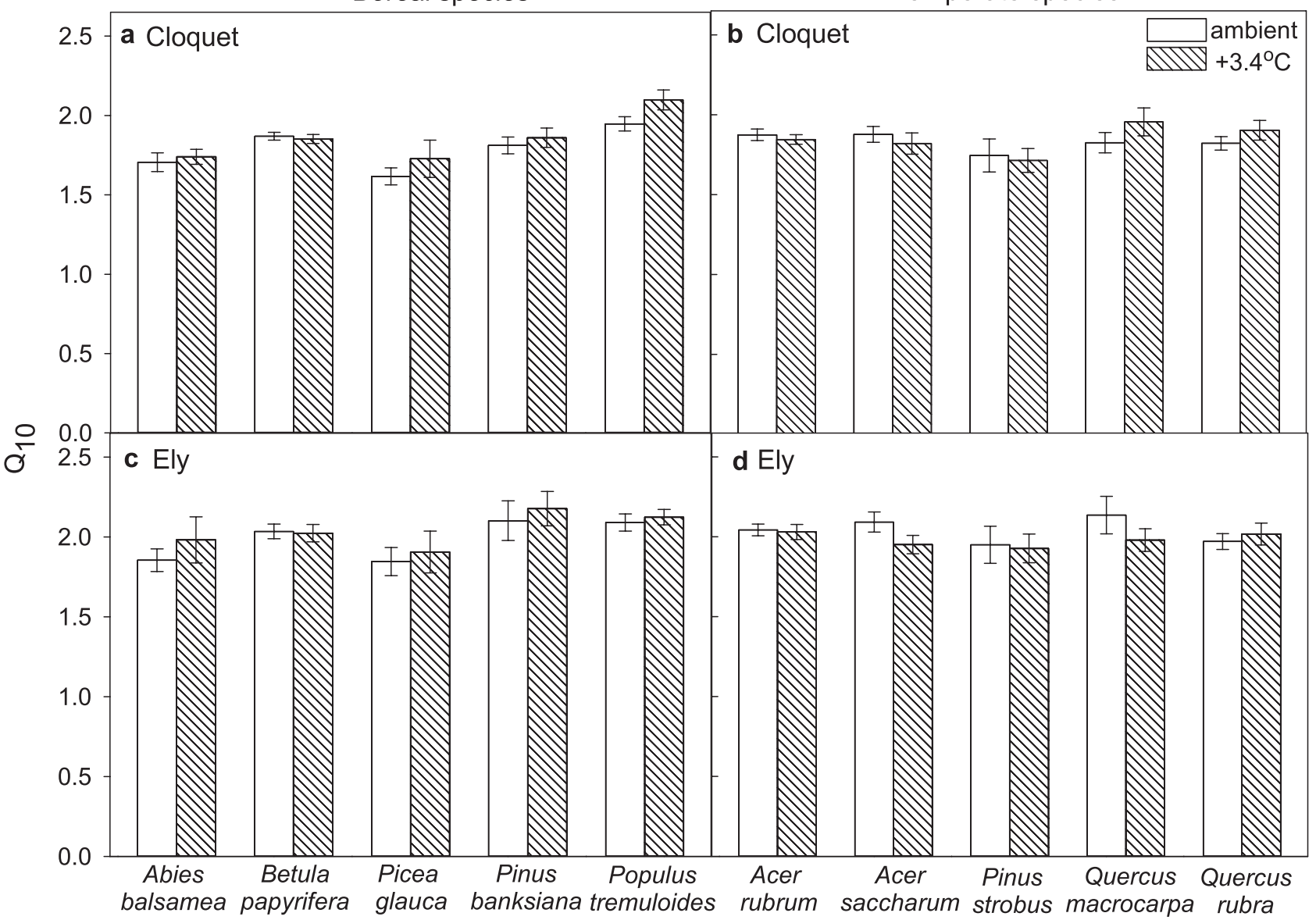

Extended Data Figure $2 \mid Q_{10}$ in ambient and experimentally warmed treatments. a-d, $Q_{10}$ (exponent of the short-term temperature response function, equation (1)) of ambient and experimentally warmed plants of all 10 species, shown for each site (grouped by biome affiliation of the species). Sample size by biome type, site, and warming treatment:

boreal, Cloquet $(\mathbf{a})$, ambient $=194$, warmed $=206$; temperate, Cloquet $(\mathbf{b})$, ambient $=244$, warmed $=247$; boreal, Ely $(\mathbf{c})$, ambient $=169$,

warmed $=174$; temperate, Ely $(\mathbf{d})$, ambient $=190$; warmed $=196$. Data are mean and s.e.m. 


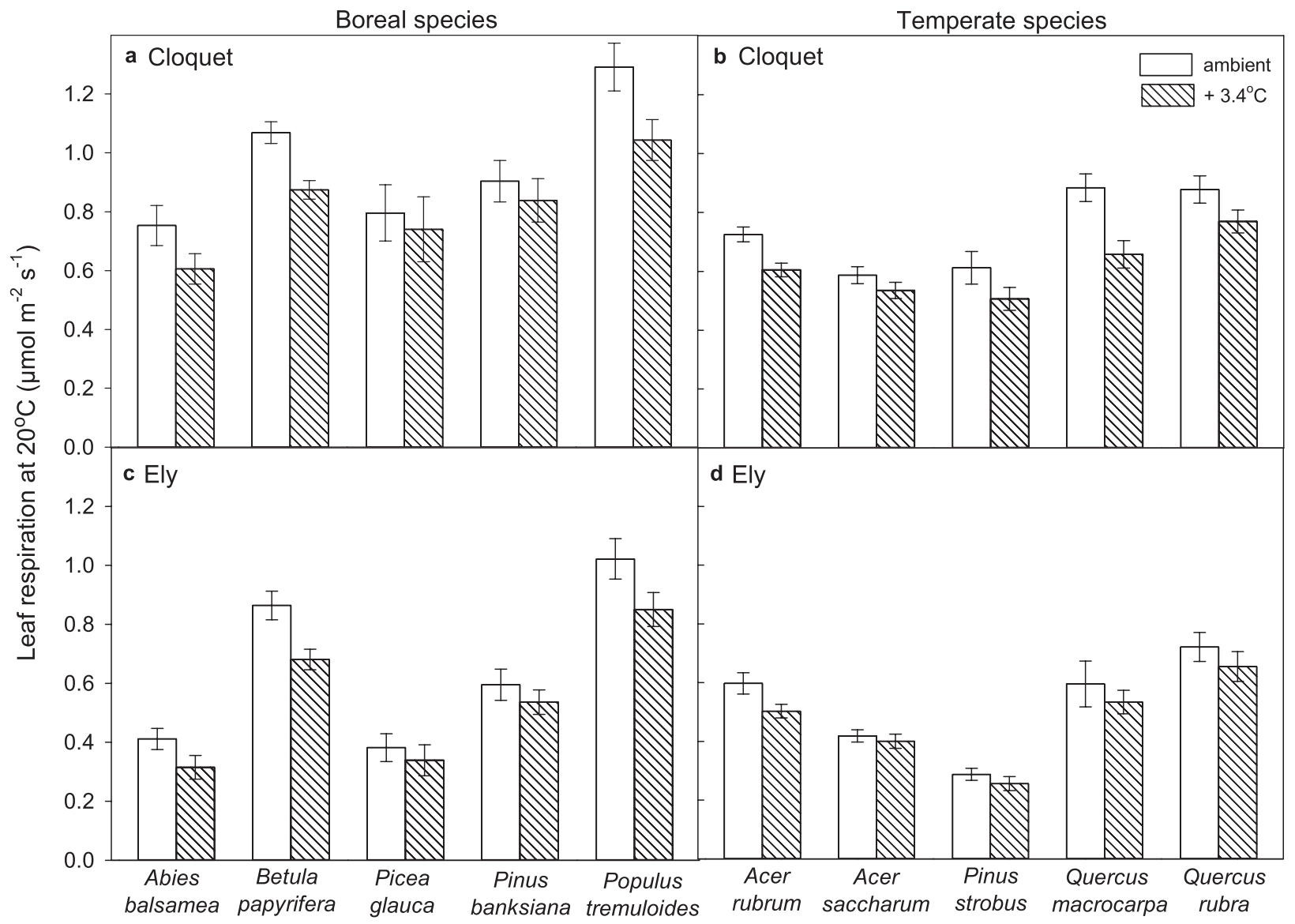

Extended Data Figure 3 Leaf dark respiration rate using $Q_{10}$ approach, $\quad$ site (grouped by biome affiliation of the species). Sample size by biome at a standardized measurement temperature, for ambient and experimentally warmed plants. a-d, Mean (and s.e.m.) leaf respiration at $20^{\circ} \mathrm{C}\left(R_{20}\right)$ of ambient and experimentally warmed plants of all 10 species. Data derived from equation (1) ( $Q_{10}$ approach) shown for each type, site, and warming treatment: boreal, Cloquet (a), ambient $=194$, warmed $=206$; temperate, Cloquet $(\mathbf{b})$, ambient $=244$, warmed $=247$; boreal, Ely $(\mathbf{c})$, ambient $=169$, warmed $=174$; temperate, Ely $(\mathbf{d})$, ambient $=190$; warmed $=196$. 


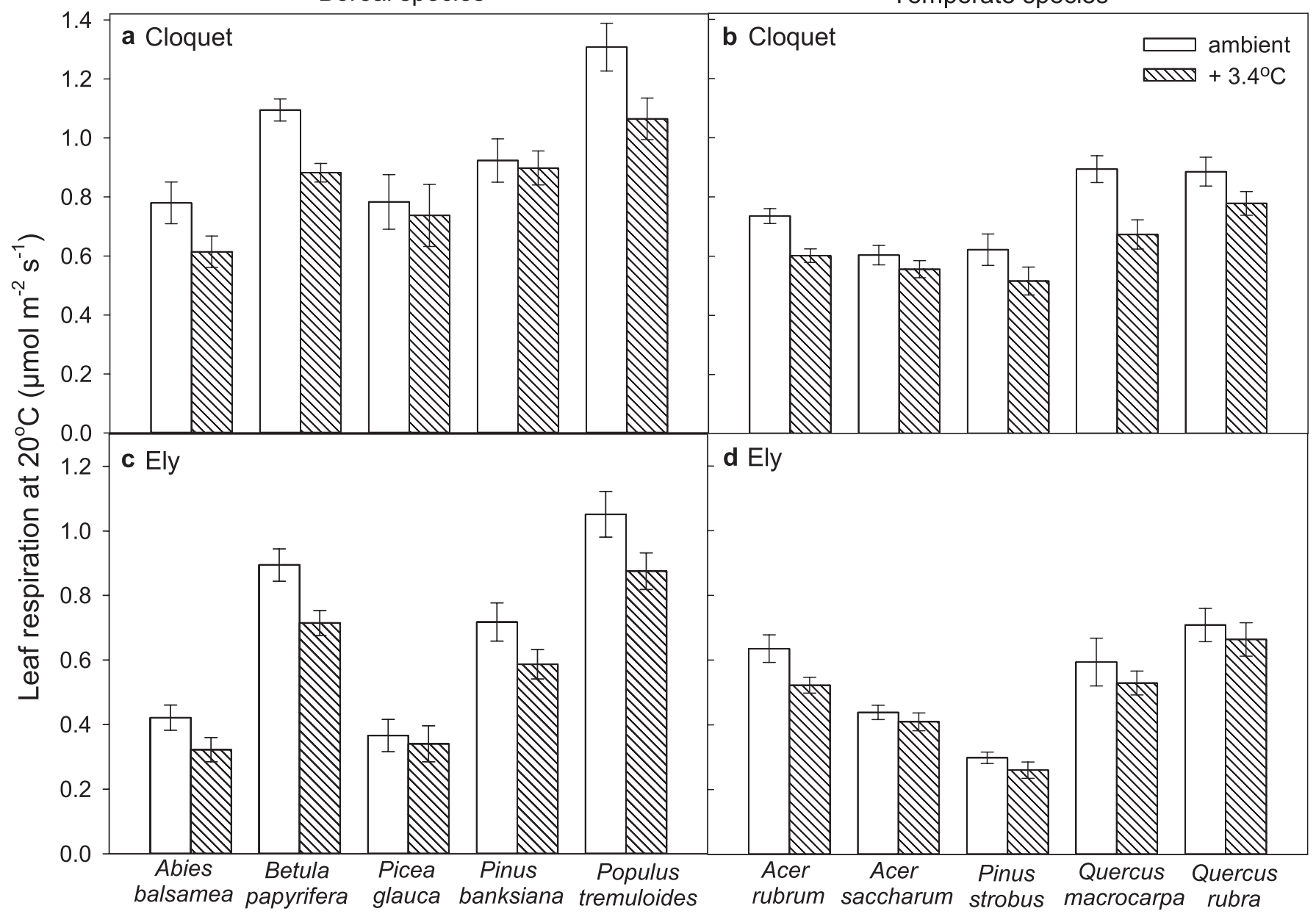

Extended Data Figure 4 | Leaf dark respiration rate using MichaelisMenton approach, at a standardized measurement temperature, for ambient and experimentally warmed plants. a-d, Mean (and s.e.m.) leaf respiration at $20^{\circ} \mathrm{C}\left(R_{20}\right)$ of ambient and experimentally warmed plants of all 10 species. Data derived from equation (6) shown for each site (grouped by biome affiliation of the species). Sample size by biome type, site, and warming treatment: boreal, Cloquet (a), ambient $=194$, warmed $=206$; temperate, Cloquet $(\mathbf{b})$, ambient $=244$, warmed $=247$; boreal, Ely $(\mathbf{c})$, ambient $=169$, warmed $=174$; temperate, Ely $(\mathbf{d})$, ambient $=190$; warmed $=196$. 


\section{RESEARCH LETTER}

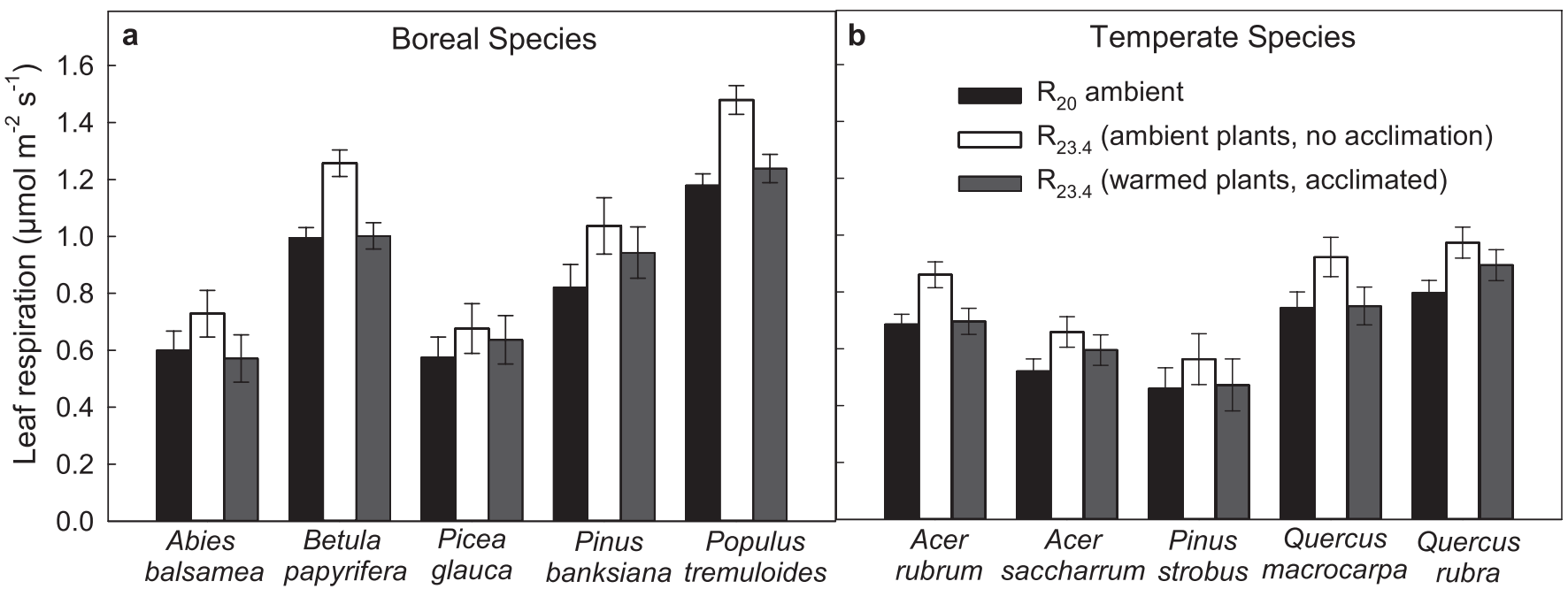

Extended Data Figure 5 | Leaf dark respiration rate of ambient and experimentally warmed plants. a, b, Data are from five boreal (a) and five temperate (b) tree species. Figure is identical to Fig. 1 except fits were made using equation (6) (Michaelis-Menton model approach) instead of equation (1) ( $Q_{10}$ approach). Respiration is shown at measurement temperatures of $20^{\circ} \mathrm{C}$ and $23.4^{\circ} \mathrm{C}$ for ambient-grown plants; respiration for plants grown at $+3.4^{\circ} \mathrm{C}$ conditions is shown at measurement temperature of $23.4^{\circ} \mathrm{C}$. The two values for ambient plants show the increase in respiration with a $+3.4^{\circ} \mathrm{C}$ temperature increase for nonacclimated plants; comparison of ambient plants measured at $20^{\circ} \mathrm{C}$ with warmed plants measured at $23.4^{\circ} \mathrm{C}$ represents the increase in respiration with a $+3.4^{\circ} \mathrm{C}$ temperature increase for acclimated plants. Data are mean and s.e.m. (s.e.m. are from the full model). Sample sizes as in Fig. 2. 


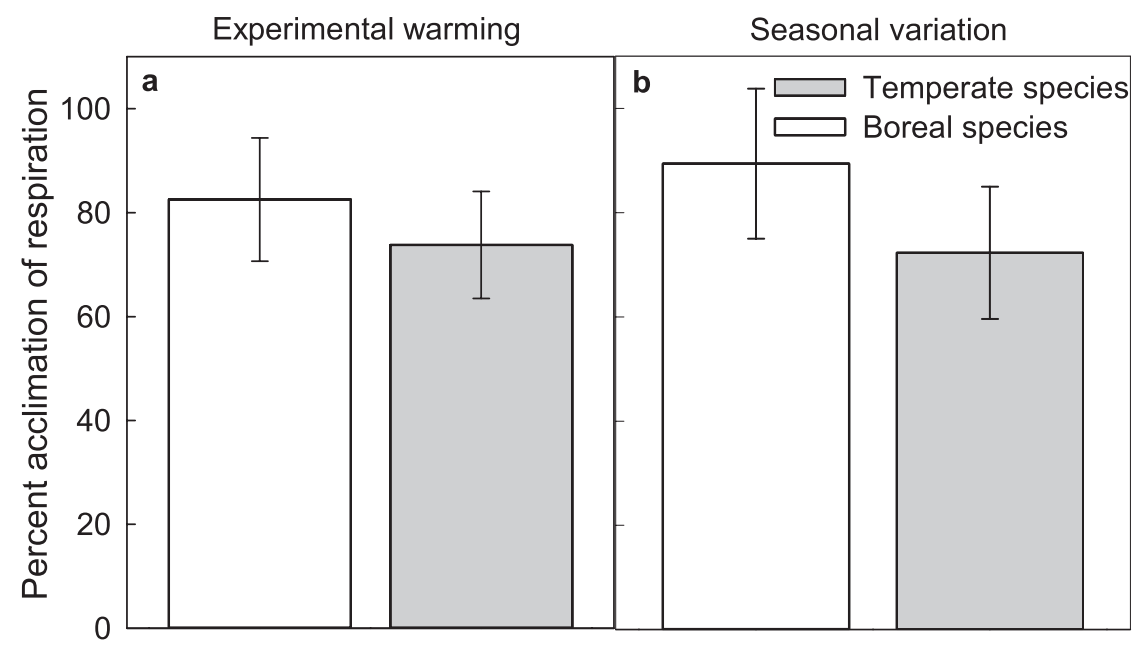

Extended Data Figure 6 Percentage acclimation by biome, in response to both experimental warming and seasonal temperature variation. a, Experimental warming. b, Seasonal temperature variation. Data are mean and s.e.m. Sample sizes as in Fig. 2. Percentage acclimation is calculated according to equation (2). 


\section{RESEARCH LETTER}

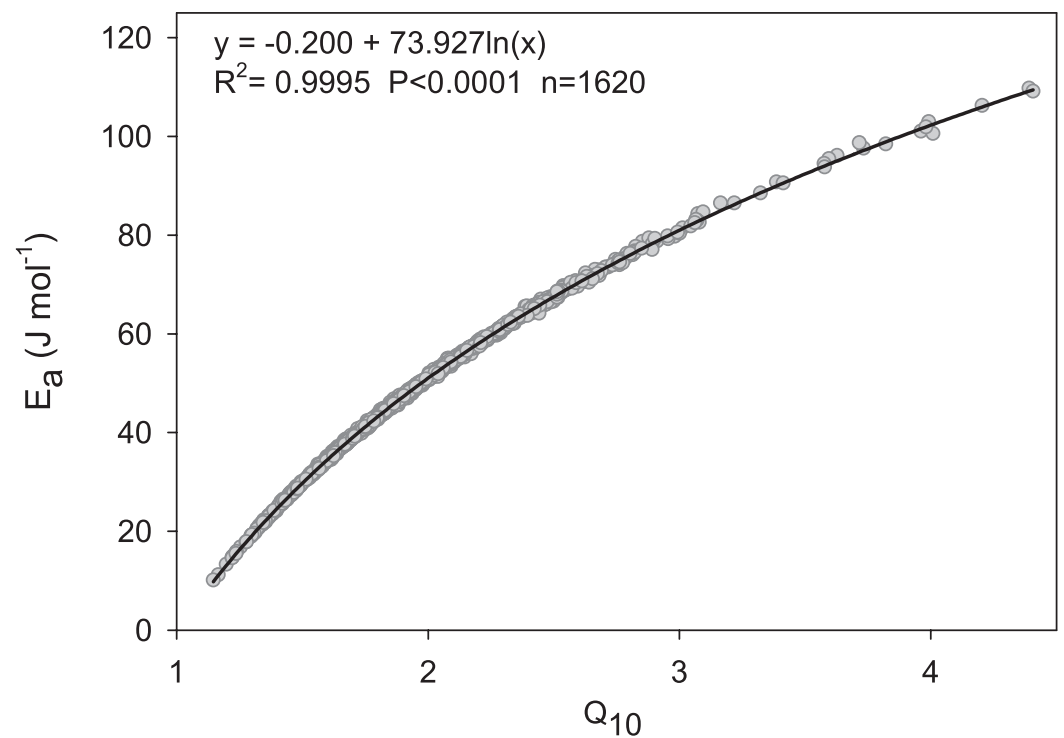

Extended Data Figure $7 \mid$ Relationship between $Q_{10}$ and activation energy of respiration $\left(E_{a}\right)$. Graph shows relationship between the exponent of the short-term temperature response function $\left(Q_{10}\right.$; from equation (1)), and the activation energy of respiration $\left(E_{a}\right)$ from the Arrhenius model (equation (3)). $n=1,620$. 


\section{LETTER RESEARCH}

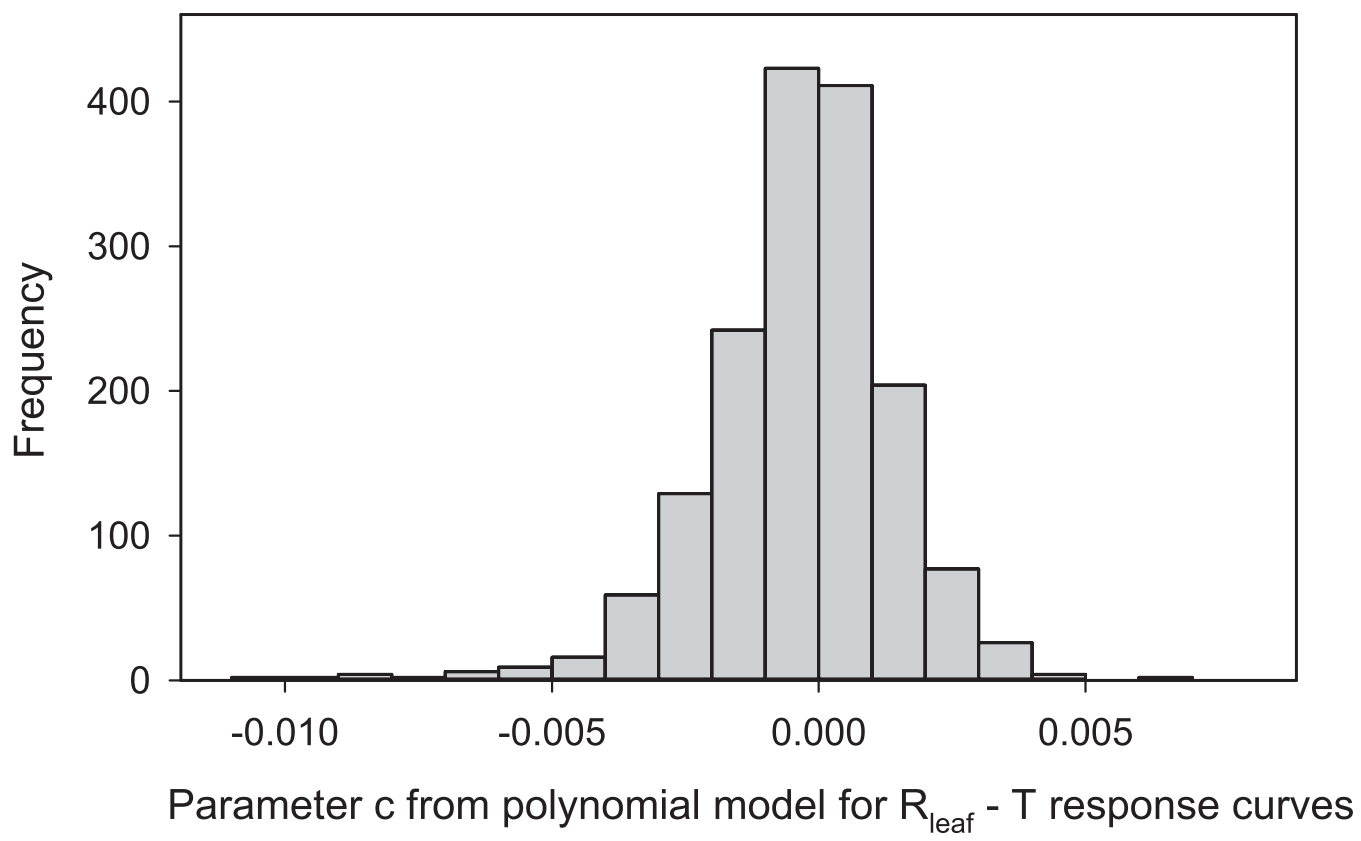

Extended Data Figure 8 | Frequency distribution of parameter $c$ from the log polynomial model (equation 5) for the respiration-temperature response curve. Among the 1,620 curves, 894 curves had $c<0,726$ curves had $c>0$. Negative $c$ values support the idea of a decelerating function (with a decreasing temperature-sensitive $Q_{10}$ ); positive values support an accelerating function. The inconsistency of $c$ being negative indicates a lack of support for a decelerating function, and thus a lack of support for the decelerating log polynomial model as useful for the data in this paper. 


\section{RESEARCH LETTER}

Extended Data Table 1 | Mean and median $R^{2}$ and r.m.s.e. of four models

\begin{tabular}{|c|c|c|c|c|}
\hline Models & $\mathrm{Q}_{10}$ model & Arrhenius model & Polynomial model & M-M model \\
\hline Mean $\mathrm{R}^{2}$ & 0.93 & 0.93 & 0.96 & 0.96 \\
\hline Median $\mathrm{R}^{2}$ & 0.95 & 0.95 & 0.97 & 0.97 \\
\hline RMSE & 0.17 & 0.17 & 0.15 & 0.15 \\
\hline Is shape consistent? & na & na & No & No \\
\hline
\end{tabular}

1: $Q_{10}$ model; 3: Arrhenius model; 5: log-polynomial model; and 6: Michaelis-Menton model for fitting respiration-temperature response curves ( $\left.n=1,620\right)$. The temperature-sensitive Arrhenius equation (equation (4)) was similar to model 3 and is therefore not included. 
Extended Data Table 2 | Species-specific equations relating $\log \left(R_{20}\right)$ to the prior 5-night temperature

\begin{tabular}{|l|c|}
\hline Species & Equation \\
\hline Abies balsamea & $0.1757-0.0301^{* \mathrm{~T}}$ \\
\hline Acer rubrum & $0.0047-0.0171^{* \mathrm{~T}}$ \\
\hline Acer saccharum & $-0.0804-0.0171^{* \mathrm{~T}}$ \\
\hline Betula papyrifera & $0.1610-0.0171^{* \mathrm{~T}}$ \\
\hline Picea glauca & $0.1424-0.0301^{* \mathrm{~T}}$ \\
\hline Pinus banksiana & $0.3332-0.0301^{* \mathrm{~T}}$ \\
\hline Pinus strobus & $0.0162-0.0301^{* \mathrm{~T}}$ \\
\hline Populustremuloides & $0.2154-0.0171^{* \mathrm{~T}}$ \\
\hline Quercus macrocarpa & $0.0533-0.0171^{* \mathrm{~T}}$ \\
\hline Quercus rubra & $0.1110-0.0171^{* \mathrm{~T}}$ \\
\hline
\end{tabular}

We tested the model for $R_{20}$ with independent predictors of phylogenetic group (angiosperm versus gymnosperm), prior temperature and their interaction. Groups differed in slope ( $P=0.0084$ ) of $R_{20}$ to the prior 5-night temperature. Models for each group separately found species did not differ in slope (no species $\times 5$-night temperature interaction) but did differ in intercept (species significant as main effect). Thus, for modelling purposes the most statistically appropriate equations are for each species to have a unique intercept, but for all gymnosperms and angiosperms to share a common slope, as derived from separate models for conifers $\left(R^{2}=0.33\right.$ for model, $\left.P<0.0001\right)$ and angiosperms $\left(R^{2}=0.27\right.$ for model, $\left.P<0.0001\right)$. 